\title{
PROPAGANDA INSTITUCIONAL Y RÉGIMEN ELECTORAL. UNA APROXIMACIÓN DESDE EL ESTUDIO DE CASOS
}

\author{
LUIS A. GÁLVEZ MUÑOZ
}


SUMARIO

I. LA TÉCNICA DEL CASO COMO INSTRUMENTO DE ANÁLISIS. II. EL CASO DE LA CAMPAÑA DE INFORMACIÓN SOBRE REVALORIZACIÓN DE PENSIONES COMO EJE DE REFLEXIÓN. 1. Puesta en marcha de la campaña. 2. Incidencias en su desarrollo. 3. Actuaciones posteriores. III. ALGUNAS CONCLUSIONES. 1. La reducida legitimidad de los poderes públicos para realizar campañas institucionales. 2. La limitada capacidad de reacción del ordenamiento jurídico. 3. La necesidad de actuar. 


\title{
PROPAGANDA INSTITUCIONAL Y RÉGIMEN ELECTORAL. UNA APROXIMACIÓN DESDE EL ESTUDIO DE CASOS
}

\author{
POR \\ LUIS A. GÁLVEZ MUÑOZ \\ Prof. Titular de Derecho Constitucional \\ Universidad de Murcia
}

\section{LA TÉCNICA DEL CASO COMO INSTRUMENTO DE ANÁLISIS ${ }^{1}$}

El estudio de casos es una de las técnicas de enseñanza más conocidas y de mayor empuje en el mundo contemporáneo, obsesionado por la idea de integrar la teoría y la práctica. De hecho, ha sido uno de los métodos formativos más demandados en el actual proceso de implantación del Espacio Europeo de Educación Superior (EEES).

Su origen se sitúa en el ámbito del Derecho, cuando Christofher Laudell lo introdujo, en 1870, en la School of Law de la Universidad de Harward. Poco después, tras su consolidación gracias a E. Gay, director de la Harward Business School ${ }^{2}$, se extendió por todas las ramas del saber y áreas de conocimiento,

${ }^{1}$ Este trabajo se enmarca dentro del proyecto de investigación «El régimen jurídico de la jornada electoral» (Código DER2009-13249/JURI), subvencionado por el Ministerio de Ciencia e Innovación.

2 E. Gay, lo introdujo en los programas de Derecho y Legislación de la Harward Business School para preparar a personal y directivos de empresas. 
como la medicina, la ciencias empresariales, las ingenierías o la psicología, aunque con diferentes propósitos y metodologías.

El estudio de casos es también, y esto es menos conocido, un método de investigación, que se aplica en diversos ámbitos, especialmente de las ciencias sociales. En algunos de ellos, como el marketing o la logística, ha llegado a ser el método cualitativo de investigación más utilizado.

Y éste es, precisamente, el método de trabajo que voy a emplear en el presente artículo. Voy a tratar de aproximarme al régimen jurídico de las campañas institucionales en período electoral partiendo de un caso concreto, que actúe a modo de eje de reflexión y de elemento de crítica y de reformulación normativa.

Se trata de un caso real, planteado hace unos pocos años en España, que en su momento acaparó la atención de los medios de comunicación y puso en aprietos al Gobierno de entonces, el último de José M. ${ }^{a}$ Aznar. Ha estado vivo hasta hace muy poco; en concreto, las últimas actuaciones tuvieron lugar en 2008. Lo podríamos denominar, de forma resumida, como el caso de la campaña de información sobre revalorización de pensiones.

\section{EL CASO DE LA CAMPAÑA DE INFORMACIÓN SOBRE REVALORIZACIÓN DE PENSIONES COMO EJE DE REFLEXIÓN}

\section{Puesta en marcha de la campaña}

a) El Instituto Nacional de la Seguridad Social (en adelante INSS) preparó en los últimos meses de 2003 la celebración de un contrato para la realización de una campaña publicitaria sobre la revalorización de las pensiones y el abono de una paga única en el ejercicio 2004. Se trataba, con ello, de informar a los pensionistas de la Seguridad Social, y a la sociedad en general, de la compensación económica que aquellos iban a recibir como consecuencia de la desviación del Índice de Preciso de Consumo (IPC) efectivo respecto del inicialmente previsto, así como de la cuantía resultante de su consolidación y de la posterior revalorización de las pensiones con efectos del 1 de enero de 2004.

El contrato fue adjudicado, en un importe de 7.212 miles de euros, por el Director General del INSS el 30 de diciembre de 2003, y formalizado por este mismo y la empresa adjudicataria el 8 de enero de 2004. De acuerdo con los pliegos del contrato, la campaña de publicidad debía desarrollarse en un plazo máximo de treinta días a contar desde la firma; no obstante, este plazo fue 
posteriormente precisado por el INSS de forma que la campaña debía desarrollarse íntegramente en 14 días, entre los días 11 y 25 de enero de 2004.

b) Esta campaña publicitaria se superpuso parcialmente en el tiempo con la notificación individualizada por carta a todos y cada uno de los pensionistas de la revalorización de sus pensiones (así como la entrega de certificación, a efectos impositivos, de las rentas abonadas en el ejercicio y las retenciones practicadas). Esta comunicación personal, cuya realización era obligada en aplicación del artículo 6 de la Resolución de la Secretaría General de la Seguridad Social de 17 de enero de 1996, por la que se establecen nuevas medidas de mejora de la gestión de la Seguridad Social y de la atención e información prestada al ciudadano, estaba prevista para el mes de enero de cada año ${ }^{3}$. La misma fue objeto, por lo demás, de la celebración de otro contrato, el cual fue adjudicado en 748 miles de euros, es decir, aproximadamente el $10 \%$ del presupuesto de la campaña publicitaria que ahora examinamos.

El INSS justificó la realización de la campaña publicitaria en esta misma Resolución de la Secretaría General de la Seguridad Social de 17 de enero de 1996. No obstante, en esta Resolución no hay precepto alguno que aluda a campañas de publicidad. Dicha Resolución únicamente obligaba al INSS a realizar a los pensionistas las notificaciones individualizadas de los incrementos de las pensiones y a remitir a cada perceptor de pensiones el correspondiente certificado, a efectos del Impuesto sobre la Renta de las Personas Físicas (IRPF), de las rentas abonadas en el ejercicio y las retenciones practicadas, pero no le obligaba a realizar ninguna campaña de difusión general dirigida a toda la población española.

${ }^{3}$ El artículo 6 la Resolución de la Secretaría General de la Seguridad Social de 17 de enero de 1996, por la que se establecen nuevas medidas de mejora de la gestión de la Seguridad Social y de la atención e información prestada al ciudadano, dice así:

«1. El Instituto Nacional de la Seguridad Social y el Instituto Social de la Marina, en el marco de sus respectivas competencias y antes de finalizar el mes natural siguiente a aquel en que se apruebe la norma correspondiente, notificarán individualmente a los pensionistas del sistema de Seguridad Social la revalorización de sus pensiones.

En la citada notificación deberán figurar como datos mínimos: El importe integro de la pensión en el ejercicio anterior a la revalorización, el porcentaje y cuantía en que se revaloriza la pensión, el importe íntegro de la pensión una vez revalorizada que se percibirá durante el nuevo ejercicio y las retenciones que, en su caso, procedan.

2. Los organismos señalados en el número anterior enviarán a los pensionistas, dentro de los cuatro primeros meses de cada año, certificación acreditativa del importe total de las cuantías percibidas en cada ejercicio y de las retenciones practicadas, a efectos de la declaración anual del Impuesto sobre la Renta de las Personas Físicas». 
c) El contrato fue objeto, en los ochos días siguientes a la formalización, de hasta tres modificaciones en la ejecución prevista, las tres por iniciativa del INSS $^{4}$ y sin que conste justificación alguna de las razones que las determinaron ${ }^{5}$ :

- La primera modificación, efectuada el viernes día 9 de enero de 2004, día siguiente al de la formalización del contrato (8 de enero de 2004), tuvo por objeto variar la distribución de medios de comunicación social para aumentar la publicidad exterior (vallas y marquesinas) y disminuir los anuncios en prensa.

- La segunda modificación, efectuada el jueves día 15 de enero, fue para introducir en la «creatividad» de la campaña, basada hasta entonces en el lema «Un año más cumplimos», un nuevo lema añadido, «Lo nuestro son las personas», y, además, incorporar el logotipo del Ministerio de Trabajo y Asuntos Sociales.

- La tercera modificación, realizada el viernes día 16 de enero, varió nuevamente la distribución de los medios publicitarios utilizados, disminuyendo los anuncios en televisión y las inserciones en prensa e incrementando, por contra, la publicidad en revistas y suplementos dominicales.

d) En el diseño de la plataforma de comunicación y de los objetivos institucionales que desarrolló la empresa adjudicataria en su oferta técnica, de acuerdo con el pliego de prescripciones técnicas particulares del contrato, se ponen claramente de manifiesto los mensajes que se pretendían proyectar. Eran dos:

- Por un lado, que «el Ministerio de Trabajo y Asuntos Sociales ha sabido reconocer y atender las necesidades de los ciudadanos, llevando a cabo mejoras para garantizar un nivel digno de ingresos de los pensionistas, manteniendo su poder adquisitivo y mejorando su calidad de vida».

- Y, por otro lado, se trataba de «demostrar la gran capacidad y sensibilidad del Ministerio de Trabajo y Asuntos Sociales en reconocer y atender las necesidades de la sociedad», "consolidar la relación con los ciudadanos, especialmente con los pensionistas», "fomentar la seguridad y con-

${ }^{4}$ Las modificaciones fueron decididas por el INSS con la participación del gabinete de comunicación del Ministerio de Trabajo y Asuntos Sociales.

${ }^{5}$ Además, las modificaciones contractuales se hicieron sin la previa adopción de acuerdos formales por parte del órgano de contratación (Director General del INSS). Todo ello en infracción del artículo 101 del Texto Refundido de la Ley de Contratos de las Administraciones Públicas entonces vigente (TRLCAP), aprobado por Real Decreto Legislativo 2/2000, de 16 de junio. 
fianza de los ciudadanos con el Ministerio de Trabajo y Asuntos Sociales», $y$ "potenciar el conocimiento de los esfuerzos, acciones e inversiones realizados por el Ministerio de Trabajo y Asuntos Sociales a través del INSS para mejorar la calidad de vida de los pensionistas y garantizar el mantenimiento del poder adquisitivo».

\section{Incidencias en su desarrollo}

a) El día 9 de enero de 2004, esto es, un día después de la celebración del contrato, el entonces Portavoz del Gobierno ${ }^{6}$ dio cuenta en rueda de prensa de que el Presidente del Gobierno había informado al Consejo de Ministros de ese día, de que la fecha de celebración de las próximas elecciones generales sería el día 14 de marzo de 2004, añadiendo que la convocatoria se publicaría en el Boletín Oficial del Estado (BOE) el siguiente día 20, como de hecho ocurrió. Dicha información fue ampliamente difundida por los medios de comunicación social ${ }^{7}$.

Se produjo así un solapamiento previsible entre las fechas finales de difusión de la campaña publicitaria (que debía desarrollarse entre el 11 y el 25 de enero de 2004) y los primeros días del período electoral (que transcurrió entre el 20 de enero y el 14 de marzo de 2004), solapamiento que no fue corregido por el INSS, teniendo oportunidad para ello, en ninguna de las tres modificaciones contractuales que experimentó este contrato entre el 9 y el 16 de enero de 2004, a las que se ha hecho referencia antes, todas ellas efectuadas una vez conocido el día 9 que se iba a producir el citado solapamiento. Debe destacarse que en otras campañas publicitarias realizadas por el Ministerio de Trabajo y Asuntos Sociales al mismo tiempo que ésta del INSS sobre las pensiones del año 2004, sí previó este Ministerio su oportuna finalización el día 20 de enero de 2004, esto es, el mismo día en que se inició el período electoral.

b) Nada más comenzar la campaña de difusión en cuestión diversos partidos políticos se quejaron de su contenido partidista, poniendo de manifiesto la especial gravedad de la realización de una campaña de este tipo en la cercanía de la

${ }^{6}$ El Portavoz del Gobierno era en ese momento, precisamente, el Ministro de Trabajo y Asuntos Sociales: el Sr. don Eduardo Zaplana Hernández-Soro.

7 El Presidente del Gobierno, previa la preceptiva deliberación del Consejo de Ministros de 19 de enero, propuso al Rey la disolución de las Cortes, quien promulgó y sancionó el Real Decreto 100/2004, de 19 de enero. 
convocatoria electoral. El Partido Socialista Obrero Español e Izquierda Unida dieron un paso más e interpusieron la oportuna reclamación ante la Junta Electoral Central (en adelante JEC), solicitando la suspensión inmediata de la campaña y la incoación de expediente sancionador a las personas responsables de la difusión de la citada campaña.

La JEC resolvió la reclamación el mismo día en que iniciaba el período electoral (20 de enero) y, por tanto, la competencia de la propia Junta, y lo hizo decretando la inmediata suspensión de la ejecución de la campaña. El máximo órgano de la Administración Electoral española entendió que la difusión de la campaña durante el período electoral era improcedente, pues, de acuerdo con la Instrucción de la propia Junta de 13 de septiembre de 1999, sobre el objeto y los límites de las campañas institucionales, publicada en el Boletín Oficial del Estado (BOE) de 16 de septiembre de 1999, dictada al amparo del artículo 8.1 de la $\mathrm{LOREG}^{8}$, dicha campaña no resultaba imprescindible para la salvaguarda del interés público ni para el correcto desenvolvimiento de los servicios públicos.

Los términos del Acuerdo son los siguientes:

«Visto que las campañas objeto de las reclamaciones han continuado publicándose en el día de hoy en que se inicia el período electoral y, por tanto, la competencia de esta Junta, trasladar a los reclamantes y al Ministerio de Trabajo y Asuntos Sociales que deberá suspenderse hasta la terminación del proceso electoral la publicación y realización de las campañas objeto de las reclamaciones por cuanto la Junta entiende, en los términos del apartado $2^{\circ}$ de la Instrucción de 13 de septiembre de 1999, sobre el objeto y los límites de las campañas institucionales, que las que son objeto del presente acuerdo, no siendo de las previstas en el artículo 50.1 de la LOREG, no resultan imprescindibles para la salvaguarda del interés público o para el correcto desenvolvimiento de los servicios públicos»?

${ }^{8}$ El artículo 8.1 de la LOREG, que es el primero de los dedicados a la Administración Electoral y que tiene carácter básico de conformidad con la Disposición adicional primera, número 2, de la misma Ley dice así: «La Administración Electoral tiene por finalidad garantizar en los términos de la presente Ley la transparencia y objetividad del proceso electoral y del principio de igualdad».

9 Este Acuerdo de la JEC de 20 de enero de 2004 fue emitido en relación con las «solicitudes de la representación de Izquierda Unida de inmediata suspensión de difusión de supuestas campañas publicitarias de balance de gestión del Gobierno y precampaña electoral del Partido Popular, a los efectos de no vulnerar los principios de igualdad, transparencia y objetividad que debe regir en los periodos de precampaña electoral que recoge el artículo 8 de la Ley Orgánica 5/1985, de 19 de junio, del Régimen Electoral General (en adelante, LOREG), y de la representación del Partido Socialista Obrero Español de suspensión inmediata de supuesta campaña electoral realizada por el Ministerio de Trabajo y Asuntos Sociales y de incoación de expediente sancionador a las personas responsables de la difusión de la citada campaña». 
Obsérvese que la JEC no suspende la campaña porque tenga una connotación partidista o electoralista y vulnere, en consecuencia, «los principios de objetividad y transparencia del proceso electoral y el principio de igualdad entre los actores electorales», como establece la Instrucción de la JEC de 13 de septiembre de 1999, al amparo del artículo 8 de la LOREG, sino por otra razón. Lo hace porque la campaña «no resulta imprescindible para la salvaguarda del interés público o para el correcto desenvolvimiento de los servicios públicos» ${ }^{10}$.

Esto supone, a mi juicio, un entendimiento inadecuado por la JEC de su propia Instrucción de 1999, pues, en la lógica de ésta, la condición de que la campaña no sea imprescindible para el interés público es un mero refuerzo o indicio que opera sobre el presupuesto de que la campaña sea electoralista ${ }^{11}$. El lector juzgará, por sí mismo, a la luz de la Instrucción, que dice así:

«1 ${ }^{\circ}$. La Administración Electoral tiene por finalidad garantizar los principios de objetividad y transparencia del proceso electoral y el principio de igualdad entre los actores electorales.

Con el fin de hacer efectivos dichos principios y sin perjuicio de que en cada caso se resuelvan por esta Junta Electoral Central los supuestos concretos que se le planteen, en función de las circunstancias concurrentes, no puede realizarse por los poderes públicos ninguna campaña durante el período electoral que atente contra los citados principios.

Se entiende por período electoral el comprendido entre la convocatoria de las elecciones y el día mismo de la votación.

$2^{\circ}$. En el criterio fijado en la norma anterior, no se entienden incluidas, siempre que no se violen tampoco dichos principios y no se dirijan directa o indirectamente, mediata o inmediatamente, a inducir el sentido del voto de los electores:

a) Las expresamente previstas en la normativa electoral en relación con la información a los ciudadanos sobre la inscripción en las listas del censo electoral o las demás previstas en el artículo 50.1 de la LOREG y concordantes, en su caso, de las leyes electorales de las Comunidades Autónomas.

b) Las que puedan resultar imprescindibles para la salvaguarda del interés público o para el correcto desenvolvimiento de los servicios públicos».

${ }^{10}$ La decisión de la JEC parece responder más bien a la lógica del Acuerdo de la propia Junta de 24 de febrero de 1995, más restrictivo que la posterior Instrucción de 1999. Sobre la evolución de la doctrina de la JEC vid. FERNÁNDEZ SEGADO, F.: «El régimen jurídico de las campañas institucionales», Corts, núm. 8, extraordinario, 1999, pp. 237 y ss.

11 De esta forma de actuar de la JEC, que se ha dado en varios casos, me he ocupado en otro trabajo, de reciente publicación. Vid. GÁLVEZ MUÑOZ, L. A.: Las campañas institucionales. Normas, doctrina de la JEC y jurisprudencia, Cizur Menor, Aranzadi, 2010, p. 62. 
Hay que anotar también que la JEC procede a la suspensión de la campaña sin que esta medida esté expresamente prevista en ninguna norma. No obstante, y aunque el tema es discutible, se considera mayoritariamente en la doctrina que el artículo 8 de la LOREG, que atribuye genéricamente a la Administración Electoral la finalidad de "garantizar en los términos de la presente Ley la transparencia y objetividad del proceso electoral y del principio de igualdad», constituye habilitación suficiente para que la JEC pueda adoptar las medidas que estimara precisas para el logro de este importante fin ${ }^{12}$.

Y otra observación de interés sobre este Acuerdo: la JEC no dice nada en él sobre la solicitud de apertura de procedimiento sancionador contra el responsable de la difusión de la campaña; ni la estima, ni la desestima formalmente, si bien, lógicamente, el silencio debe entenderse en sentido negativo. La Junta tampoco abordó esta cuestión con posterioridad, ante el recurso presentado por la representación del Partido Socialista Obrero Español solicitando «incoar los correspondientes expedientes sancionadores y deducir testimonio por si dichas conductas pudieran ser constitutivas de un delito tipificado en el artículo 404 del Código Penal», por considerar que dicho recurso era extemporáneo ${ }^{13}$.

c) Como consecuencia del Acuerdo de la JEC de 20 de enero de 2004 de suspensión de la ejecución de esta campaña publicitaria, el INSS se vio obligado, por su parte, a suspender de forma inmediata el contrato celebrado. Lo hizo el 21 de enero, si bien el día anterior, cuatro horas más tarde de recibir la notificación del acuerdo de suspensión por parte de la Junta, adelantó su decisión y notificó a la correspondiente empresa de comunicación la suspensión del contrato de difusión de la campaña.

12 En este sentido vid. ARNALDO ALCUBILLA, E.: «La interpretación de la normativa electoral por la JEC (1977-1997)», Revista de las Cortes Generales, núm. 41, 1997, pp. 179-180. En contra vid. SOLER SÁNCHEZ, M.: "Las problemáticas campañas institucionales en el período electoral», Corts, núm. 8, extraordinario, 1999, pp. 371-372 y 378; CARRILLO, M.: «Información y período electoral», en MUÑOZ MACHADO, S., y ROSPIR, A. (ed.), Democracia mediática y campañas electorales, Ariel, Barcelona, 1999, pp. 218-219; y DELGADO-IRIBARREN GARCÍA-CAMPERO, M.: «La Administración Electoral», en VV.AA., Derecho Contencioso electoral, Cuadernos de Derecho Judicial, XI-2001, pp. 92-93.

13 Se trata del Acuerdo de 10 de febrero de 2004, cuyo texto dice así: «Inadmitir el recurso por extemporáneo, dado que se refiere a actuaciones realizadas el 20 de enero de 2004 y el recurso tiene entrada en esta JEC el día 4 de febrero de 2004 año, sin que la perentoriedad de las actuaciones en período electoral permita la aplicación supletoria de los preceptos de la legislación de procedimiento administrativo relativos a la presentación de escritos en determinadas dependencias». 
Esta suspensión no consiguió evitar, sin embargo, la difusión de las inserciones publicitarias previstas mediante la publicación de anuncios en revistas puestas a la venta en fecha posterior a la de la suspensión de la campaña. Y es que, en razón de los usos de los medios de comunicación escritos en cuanto a la producción de los habituales suplementos de los fines de semana, no resultaba nada fácil impedir la aparición de la campaña prohibida en los mismos.

Algunos grupos políticos denunciaron la situación como vulneración del Acuerdo de suspensión de la JEC, pero este órgano no lo estimó así, por entender que no se trataba de una nueva campaña del Ministerio de Trabajo idéntica a la anterior, sino de inserciones de la campaña anterior en semanarios, cuya difusión posterior al Acuerdo de suspensión era imposible de evitar. El Acuerdo de la Junta, de 29 de enero de 2009, dice así:

«Desestimar la reclamación por cuanto, de los antecedentes obrantes en las actuaciones, resulta que aproximadamente cuatro horas más tarde de recibir la notificación del acuerdo de suspensión de la campaña de referencia adoptado por esta Junta en reunión del 20 de enero de 2004, la Administración competente notificó a la correspondiente empresa de comunicación la suspensión del contrato de difusión de la campaña, sin que, por razón de los usos de los medios en cuanto a la producción de los habituales suplementos de los fines de semana, resultara posible evitar la aparición de la campaña en «El Semanal» que motiva la denuncia que se resuelve».

\section{Actuaciones posteriores}

a) En el mes de marzo de 2004 el INSS abrió, de acuerdo con lo dispuesto en el artículo 102 del Texto Refundido de la Ley de Contratos de las Administraciones Públicas entonces vigente, aprobado por Real Decreto Legislativo 2/2000, de 16 de junio (en adelante TRLCAP), el procedimiento para determinar «la situación de hecho» existente en la ejecución del contrato y para abonar al contratista los daños y perjuicios «efectivamente» sufridos por éste ${ }^{14}$. El procedimiento concluyó el 20 de abril con la resolución del contrato y el reconocimiento al contratista del derecho a percibir, además del precio de los servi-

14 A estos efectos, el 29 de marzo de 2004, la Dirección General del INSS ordenó la iniciación del expediente de liquidación y resolución del contrato, de conformidad con la propuesta, de 22 de marzo de 2004, de la Subdirección General del Información y Comunicación del propio INSS. 
cios realizados antes de la suspensión, una indemnización de 210.985,22 euros, equivalente al $10 \%$ del importe de los trabajos contratados y pendientes de ejecutar en el momento de la suspensión, en concepto de lucro cesante o beneficio económico dejado de obtener por la empresa adjudicataria a causa de la suspensión ${ }^{15}$.

De acuerdo con ello, la decisión del INSS de que esta campaña publicitaria extendiera su difusión hasta el 25 de enero, esto es, más allá del día 20 de enero de 2004 (fecha en la que, como ya era conocido desde el 9 de enero anterior, debía iniciarse el período electoral), provocó un coste económico a cargo del presupuesto de la Seguridad Social, determinado por la mencionada indemnización de 210.985,22 euros, que el INSS tuvo que pagar al adjudicatario por la parte de la campaña que no pudo ser emitida, al suspenderse por la JEC la difusión de la campaña en el tiempo coincidente con el período electoral. Esta indebida extensión de la campaña contrasta, como ya se ha señalado anteriormente, con el hecho de que otras campañas publicitarias realizadas al mismo tiempo por el propio Ministerio de Trabajo y Asuntos Sociales, sí previeron su oportuna finalización el día 20 de enero de 2004, justamente en la fecha en que comenzó el período electoral, por lo que no resultaron afectadas por la suspensión decretada por la JEC, y no dieron lugar a indemnización alguna.

b) Un año después el asunto llegó al Tribunal de Cuentas, en cuanto supremo órgano fiscalizador de las cuentas y de la gestión económica del Estado y de todo el sector público ${ }^{16}$. Analizó el contrato en cumplimiento del Programa de Fiscalizaciones del Tribunal de Cuentas para el año 2005, aprobado por el Pleno del Tribunal en su sesión del día 30 de marzo de 2005.

${ }^{15}$ Una vez emitido, el 15 de abril de 2004, por el Subdirector General de Información y Comunicación del INSS, el informe de valoración, comprobación y recepción de la liquidación del contrato presentada por la empresa adjudicataria, y previos los informes favorables de la Asesoría Jurídica Central del INSS (de 19.4.2004), y de la Intervención Central de la Intervención General de la Seguridad Social (IGSS) en el INSS (de 20.4.2004), de conformidad ambos con la propuesta de resolución del contrato formulada, el Director General del INSS acordó la resolución del contrato, como ha quedado señalado, el día 20 de abril de 2004, mediante Resolución que puso fin a la vía administrativa.

${ }^{16}$ El procedimiento fiscalizador llevado a cabo se enmarca en el ámbito de las competencias de fiscalización de los contratos celebrados por la Administración del Estado y las demás entidades del sector público, que el artículo 11.a) de la Ley Orgánica 2/1982, de 12 de mayo, del Tribunal de Cuentas, atribuye al mismo, dentro de la más amplia función fiscalizadora referida al sometimiento de la actividad económico-financiera del sector público a los principios de legalidad, eficiencia y economía, contemplada en el artículo 9 del mismo texto legal. 
El Tribunal de Cuentas censuró severamente, en su Informe de 16 de marzo de 2006, la actuación del INSS ${ }^{17}$. Consideró que no estaba justificada en modo alguno la necesidad de realización de la campaña objeto del contrato, que la misma fue claramente partidista y que su prohibición por la JEC, una vez comenzado el período electoral, era previsible, lo que provocó un innecesario coste económico a la Seguridad Social.

Como consecuencia de ello, y en la medida en que el menoscabo público era previsible, el Tribunal de Cuentas consideró que había motivo suficiente para estudiar las eventuales responsabilidades contables, por lo que remitió el expediente a la Sección de Enjuiciamiento del propio Tribunal. No obstante, esta Sección acordó de oficio, dos años después, el archivo de los autos por no encontrar motivo de responsabilidad contable ${ }^{18}$.

\section{ALGUNAS CONCLUSIONES}

Del análisis que acabo de realizar del caso de la campaña de información del INSS sobre la revalorización de pensiones es posible extraer algunas conclusiones de interés sobre el régimen jurídico de la propaganda institucional en período electoral. Pueden sintetizarse en las tres siguientes.

\section{La reducida legitimidad de los poderes públicos para realizar campañas institucionales en periodo electoral}

La primera conclusión a la que cabe llegar consiste en constatar la reducida legitimidad de los poderes públicos para realizar campañas institucionales durante el período electoral, el más delicado, sin duda, de la vida política de un país. En el momento en que tuvo lugar la campaña del INSS era de aplicación la Instrucción de la JEC de 1999, y, con arreglo a ella, los poderes públicos no podían realizar ninguna campaña institucional —entendido este término en sentido amplio- que tuviera connotación electoralista. En la Instrucción se habla de que las campañas «no atenten contra los principios de objetividad y transparencia del proceso electoral y el principio de igualdad entre los actores electorales» y de que

17 Informe de fiscalización n. ${ }^{\circ}$ 706, de 16 de marzo de 2006, sobre la contratación celebrada por la Seguridad Social para la difusión de información y otros servicios de contenido.

18 Auto de 18 de febrero de 2008 del Departamento Primero de la Sección de Enjuiciamiento del Tribunal del Cuentas, del que da cuenta el Auto de 25 de abril del mismo año. 
«no se dirijan directa o indirectamente, mediata o inmediatamente, a inducir el sentido del voto de los electores». Se indica, además, expresamente, que las campañas institucionales «no podrán contener alusiones a los logros obtenidos durante su mandato por el poder público que realice la campaña ni imágenes o expresiones coincidentes o similares a las utilizadas en sus propias campañas por alguna de las entidades políticas concurrentes a las elecciones».

Esto significa que la decisión tomada por el INSS de realizar la campaña de revalorización de pensiones en coincidencia parcial con el período electoral fue incorrecta, dado su carácter electoralista; y que, de forma paralela, la decisión de la JEC de prohibirla fue ajustada a Derecho, aunque la argumentación empleada por la Junta no fuera la más correcta, como ya puse de manifiesto en su momento.

Dicho esto, conviene puntualizar que en los últimos años se ha producido un importante cambio legislativo en materia de campañas institucionales, que, sin embargo, no modifica el sentido de la respuesta. Me refiero a la Ley 29/2005, de 29 de diciembre, de publicidad y comunicación institucional (en adelante LPCI).

En el momento actual se aplica tanto la Instrucción de la JEC de 1999 como la LPCI, pues la primera sigue complementando a la segunda, dado su superior campo de aplicación ${ }^{19}$. De la primera ya he hablado y no voy a añadir nada más; y por lo que hace a la segunda hay que señalar que la misma ha establecido el principio o regla general de que los poderes públicos estatales no pueden realizar campañas institucionales en período electoral, salvo dos excepciones: las campañas de información sobre las elecciones y las campañas que resulten imprescindibles para la salvaguarda del interés público o para el correcto desenvolvimiento de los servicios públicos. Además, prohíbe en todo momento, y no solo durante el período electoral, las campañas de autobombo, las que puedan

${ }^{19}$ La LPCI no ha derogado, en ninguno de sus puntos, a la regulación anterior. Sólo ha afectado parcialmente a la Instrucción de la JEC de 13 de septiembre de 1999. Esta Instrucción tiene ciertas discordancias con la LPCI, pero sigue estando vigente, en la medida en que tiene un ámbito de aplicación más amplio que la LPCI: afecta a todas las Administraciones Públicas (la LPCI afecta, en cambio, como regla general, únicamente a la Administración del Estado y demás sujetos integrantes del sector público estatal) y a todo tipo de campañas institucionales, incluidos los actos institucionales, como inauguraciones y similares (este tipo de actos quedan, por el contrario, fuera de la LPCI). Sobre esta cuestión vid. mi trabajo: «Los límites de la campaña institucional y la incentivación de la participación", en El Informe del Consejo de Estado sobre la reforma electoral. Texto del Informe y debates académicos, Consejo de Estado y Centro de Estudios Políticos Constitucionales, Madrid, 2009, pp. 583 y ss.; y «La Ley de publicidad y comunicación institucional y su aplicación en período electoral», en actual proceso de evaluación en orden a su publicación en revista especializada. 
confundirse con las de los partidos políticos y las de combate entre Administraciones.

Con arreglo a este nuevo esquema normativo hay que concluir que hoy habría que decir lo mismo sobre la campaña de información del INSS que en 2004, pues, además de que la campaña tenía carácter electoralista, no es de las que quepa considerar como «imprescindibles» para la salvaguarda del interés público. Habría que indicar incluso que hoy ni siquiera hubiera sido posible hacer dicha campaña publicitaria antes de las elecciones, pues se ha incorporado al ordenamiento jurídico la prohibición de hacer campañas de autopromoción durante el período político ordinario (artículo 4.1 LPCI).

\section{La limitada capacidad de reacción del ordenamiento jurídico}

La segunda conclusión que cabe extraer del estudio realizado hace referencia a la limitada capacidad del ordenamiento jurídico para impedir y reaccionar contra las infracciones que cometen los poderes públicos en este terreno. Ello afecta al diseño legislativo de los mecanismos de control, como, sobre todo, a la propia actuación de los órganos encargados de llevar a cabo este control.

Así ha quedado claramente de manifiesto, a mi juicio, en el caso estudiado: nadie pudo impedir la realización de una campaña institucional manifiestamente contraria a Derecho; cuando se prohibió por la JEC que continuara su realización, la prohibición quedó defraudada, gracias a que la campaña continuó difundiéndose en las revistas; y la infracción de la prohibición no generó responsabilidad jurídica alguna de ningún tipo para nadie: ni penal, ni administrativa, ni civil o de resarcimiento del daño ${ }^{20}$.

Esto deja un cierta, y muy negativa, sensación de debilidad del ordenamiento jurídico, de que éste no cumple su función de ordenar la realidad y reaccionar, en su caso, contra las infracciones que se produzcan, sea restableciendo la situación, sea sancionando a los responsables. Se puede tener, por ello, la impresión de que sale rentable infringir el ordenamiento jurídico, de que no hay responsabilidad jurídica efectiva para los infractores, de que la impunidad campa por sus respetos.

Con todo, la situación ha mejorado levemente en este terreno, concretamente en el aspecto del diseño legislativo de los mecanismos de control. Ello es así

${ }^{20}$ La única responsabilidad que se generó fue contractual: de la propia Administración hacia el contratista por el lucro cesante producido como consecuencia de haberse suspendido la campaña de información (más de $210.000 €$ ). 
como consecuencia del establecimiento por la LPCI (artículo 7) de una Comisión de Publicidad y Comunicación Institucional encargada de velar, a instancia de parte, por el cumplimiento de las prohibiciones establecidas en la misma.

El artículo 7 de la LPCI no es aplicable, hay que precisarlo, a las campañas institucionales que se realicen durante el período electoral, pues durante este período, en virtud del principio de especialidad, el control de las prohibiciones corresponde a las Juntas Electorales. No obstante, la Comisión de Publicidad en él establecida puede constituir un instrumento muy útil de cara a evitar comportamientos inadecuados y oportunistas de los poderes públicos durante los días anteriores a una convocatoria electoral previsible; ello repercutirá necesariamente, y de forma muy positiva, en el propio período electoral, dada la artificialidad de las fronteras en el terreno de la información y la propaganda.

\section{La necesidad de actuar}

La tercera y última conclusión enlaza con la anterior. En ella ha quedado puesto de manifiesto que los límites legales en materia de campañas institucionales en época electoral se pueden sobrepasar, y de hecho se sobrepasan, impunemente, pero también que es posible mejorar los mecanismos de control existentes. Añadimos ahora que es necesario actuar y que ello se puede hacer sin apenas costo.

¿Cómo? Propongo estas cuatro medidas, que expongo con suma brevedad, en espera de ulteriores consideraciones:

- Clarificar el ordenamiento jurídico, introduciendo las modificaciones normativas y las aclaraciones interpretativas por parte de la JEC que sean precisas. Debe quedar claro qué se puede hacer en este terreno y qué no.

- El establecimiento de controles previos de la legalidad de las campañas institucionales que se vayan a desarrollan en período electoral: Así, los proyectos de campañas podrían someterse, antes de su aprobación definitiva, a una Comisión independiente, a fin de que sus miembros pudieran opinar sobre su neutralidad y se pudiera, en consecuencia, introducir las modificaciones que se estimaran convenientes ${ }^{21}$.

- Aumentar las sanciones, de tal modo que sean disuasorias de la tentación de infringir el ordenamiento o de apurar los límites de lo admisible o, incluso, de desobedecer las decisiones de la Administración Electoral.

${ }^{21}$ Ello no eliminaría, lógicamente, el control específico y posterior de las juntas electorales. 
- Abrir de manera efectiva la vía del reintegro patrimonial del daño ocasionado a los bienes públicos por parte de los servidores públicos que sean responsables de la realización de campañas institucionales parti$\operatorname{distas}^{22}$.

Concluyo. La conflictividad que se plantea en esta materia, al igual que en otros temas de carácter electoral, puede ser comprensible, dada la enorme importancia de lo que está en juego: el acceso al poder de uno de los grupos políticos que surcan la sociedad, es decir, la posibilidad de gobernar y, con ello, de dirigir el rumbo de la nación. Ahora bien, lo que ya no es tan comprensible es la fuerza de algunos embates y la falta de respuesta del legislador y de los órganos de control ante los mismos.

A veces se tiene la sensación de que durante esta fase tan importante de la vida política de un país todo o casi todo vale, con tal de que pueda dar réditos electorales, y de que los límites de la lucha política apenas existen. Y esto no es admisible; es, por el contrario, sumamente preocupante. Algo habría que hacer, por ello, pues está en juego tanto la limpieza de la lucha política y, en concreto, electoral, como la misma vigencia del Estado de Derecho.

Title

INSTITUTIONAL PROPAGANDA AND ELECTORAL REGULATIONS. AN APPROXIMATION FROM THE CASE STUDY.

\section{Sumary}

I. THE CASE STUDY AS AN INSTRUMENT TO ANALYZE. II. THE CASE OF THE PENSIONS REASSESS INFORMATION CAMPAIGN AS THE CENTER OF THE STUDY. 1. Campaign implementation. 2. Incidents during its development. 3. Subsequent actions. III. SOME CONCLUSIONS. 1. The small legitimicy of the Governmental Powers to do institucional campaigns. 2. The small capacity of reaction of the Law System. 3. The need to act.

22 Vid. el artículo 145 de la Ley 30/1992, de 30 de noviembre, de régimen jurídico y del procedimiento administrativo común, así como los artículos 19 a 21 del Reglamento de los procedimientos en materia de responsabilidad patrimonial de la Administración, aprobado por el Real Decreto 429/1993, de 26 de marzo. 


\title{
Resumen
}

En este trabajo se trata de mostrar la validez del tratamiento del caso para obtener conceptos correctos en el análisis jurídico. Concretamente, del caso de la campaña de información del INSS sobre la revalorización de las pensiones se extraen conclusiones sobre la propaganda electoral institucional.

\begin{abstract}
In this work one is to show the validity of the treatment of the case to obtain correct concepts in the legal analysis. Concretaly, of the case of the campaign of information of the INSS on the revaluation of the pensions conclusions are extracted on institutional the electoral advertiding.

\section{Palabras clave}

Campaña institucional, publicidad institucional, campaña electoral, régimen electoral, elecciones.

\section{Keywords}

Institutional campaign, Institutional publicity, electoral campaign, electoral regulations, elections.
\end{abstract}

